Article

\title{
Prediction of Forest Stand Attributes Using TerraSAR-X Stereo Imagery
}

Mikko Vastaranta ${ }^{1,2, *}$, Mikko Niemi ${ }^{1,2}$, Mika Karjalainen ${ }^{2,3}$, Jussi Peuhkurinen ${ }^{4}$, Ville Kankare $^{1,2}$, Juha Hyyppä ${ }^{2,3}$ and Markus Holopainen ${ }^{1,2}$

1 Department of Forest Sciences, University of Helsinki, Helsinki FI-00014, Finland;

E-Mails: mikko.t.niemi@ helsinki.fi (M.N.); ville.kankare@helsinki.fi (V.K.); markus.holopainen@helsinki.fi (M.H.)

2 Centre of Excellence in Laser Scanning Research, Finnish Geodetic Institute, Masala FI-02431, Finland

3 Department of Remote Sensing and Photogrammetry, Finnish Geodetic Institute, Masala FI-02431, Finland; E-Mails: mika.karjalainen@fgi.fi (M.K.); juha.hyyppa@fgi.fi (J.H.)

4 Arbonaut Oy Ltd., Latokartanontie 7 A, Helsinki FI-00700, Finland;

E-Mail: jussi.peuhkurinen@arbonaut.com

* Author to whom correspondence should be addressed; E-Mail: mikko.vastaranta@helsinki.fi; Tel.: +358-9-1915-8100.

Received: 12 January 2014; in revised form: 13 March 2014 / Accepted: 4 April 2014 / Published: 10 April 2014

Abstract: Consistent, detailed and up-to-date forest resource information is required for allocation of forestry activities and national and international reporting obligations. We evaluated the forest stand attribute prediction accuracy when radargrammetry was used to derive height information from TerraSAR-X stereo imagery. Radargrammetric elevations were normalized to heights above ground using an airborne laser scanning (ALS)-derived digital terrain model (DTM). Derived height metrics were used as predictors in the most similar neighbor (MSN) estimation approach. In total, 207 field measured plots were used in MSN estimation, and the obtained results were validated using 94 stands with an average area of 4.1 ha. The relative root mean square errors for Lorey's height, basal area, stem volume, and above-ground biomass were $6.7 \%(1.1 \mathrm{~m}), 12.0 \%\left(2.9 \mathrm{~m}^{2} / \mathrm{ha}\right)$, $16.3 \%\left(31.1 \mathrm{~m}^{3} / \mathrm{ha}\right)$, and $16.1 \%(15.6 \mathrm{t} / \mathrm{ha})$. Although the prediction accuracies were promising, it should be noted that the predictions included bias. The respective biases were $-4.6 \%(-0.7 \mathrm{~m}),-6.4 \%\left(-1.6 \mathrm{~m}^{2} / \mathrm{ha}\right),-9.3 \%\left(-17.8 \mathrm{~m}^{3} / \mathrm{ha}\right)$, and $-9.5 \%(-9.1 \mathrm{t} / \mathrm{ha})$. With detailed DTM, TerraSAR-X stereo radargrammetry-derived forest information 
appears to be suitable for providing consistent forest resource information over large areas.

Keywords: remote sensing; GIS; forestry; airborne laser scanning; radargrammetry; forest management planning; forest inventory

\section{Introduction}

Airborne and satellite remote sensing plays an important role in mapping of large remote areas. Satellite images, such as Landsat have been used to generate wall-to-wall information from field data. Several countries, such as Finland, Sweden, USA, Norway, Austria, New Zealand, China, Germany, and Italy employ or have tested this kind of approach in addition to the solely field measurement-based national forest inventory (NFI) [1]. Though there have been major advances in satellite remote sensing technologies in recent years, it has been challenging to overcome the saturation problem that makes it hard to detect forests with high above-ground biomass (AGB) or stem volume. Tuominen and Haakana [2] used Landsat 7 ETM images to predict forest attributes. Sample plots of 9th NFI of Finland were used in the calibration and validation. Mean height was among the predicted variables, and the prediction accuracy was $7.1 \mathrm{~m}$ (root mean square error, RMSE). Franco-Lopez et al. [3] obtained plot-level RMSE-accuracies of $46 \%$ and $65 \%$ for basal area and stem volume, respectively, using Landsat imagery. Holmström and Fransson [4] obtained plot-level RMSE-accuracy of 64\% for stem volume using SPOT (French: Satellite Pour l'Observation de la Terre) 4-XS imagery. Thus, due to saturation, stem volume or biomass estimation accuracy at the plot level is close to RMSE of 70\% when optical satellite images are used with field data for prediction of forest attributes.

The saturation problem in AGB estimation can be overcome by adopting airborne laser scanning (ALS). When ALS is used, laser pulses penetrate even through a dense multi-layered canopy, and there is a strong correlation between airborne laser height profiles or point clouds and AGB or stem volume (e.g., [5-11]). Lefsky et al. [6] showed that a single profiling laser-derived metric, such as the quadratic mean of the canopy height, could explain $80 \%$ of the variance in AGB. Næsset [12] used regression methods to estimate AGB for 143 sample plots in young and mature coniferous forests. In the study, regression methods explained $92 \%$ of the variability of the AGB.

In wall-to-wall forest inventories in intensively managed forest areas, a two-phase procedure using ALS data and field plots, i.e., an area-based approach (ABA, [13]), has become common [14]. The ABA is capable of providing wall-to-wall estimates and maps of forest inventory attributes, such as basal area or stem volume, with an accuracy that is better than in traditional mapping inventories $[14,15]$. However, ALS surveys required for ABA are carried out at relatively low altitudes, usually from 0.5 to $3 \mathrm{~km}$, which makes data acquisition expensive per area unit. Thus, other remotely sensed data will still be needed, especially when updated information is required annually or consistently over large areas.

Asner et al. [16], Andersen et al. [17], Gregoire et al. [18], Ståhl et al. [19], and Gobakken et al. [20] have all investigated ALS-based sampling to obtain reliable forest resource estimates for totals. In addition to sampling, other cost-efficient use of ALS is in collection of calibration and validation 
data for wall-to-wall predictions using optical image data [21]. While optical image data, such as Landsat, provide useful information on the horizontal distribution of forest canopy structure, ALS provides information on its vertical distribution. When ALS-derived forest characteristics are used in the modeling instead of traditional ground plots, more information can be acquired with the same costs. Thus, compared to ground plots, ALS plots provide more information of the distribution of the forest characteristics in the inventory area. However, some amount of ground plots is required to predict forest characteristics of the ALS plots in this approach. With this kind of procedure, stand mean height has been estimated with app. 3 m RMS-accuracy [22,23]. Recently, ALS has been used for calibration and validation of forest characteristic predictions using optical imagery [24-26]. Chen et al. [24] tested integration of Landsat imagery and ALS to estimate tree height variables. The estimation errors for mean, dominant and Lorey's height were $4.9 \mathrm{~m}, 4.1 \mathrm{~m}$ and $4.7 \mathrm{~m}$, respectively, validated at the plot level $\left(625 \mathrm{~m}^{2}\right)$. Mora et al. [25,26] used very high spatial resolution (VHSR, <1 m) optical imagery calibrated and validated with ALS to estimate forest characteristics. Stand and tree objects were delineated, followed by modeling of stand height, stem volume, and AGB using metrics derived from the stand and tree crown objects. In Mora et al. [25], only stand height was modeled, and RMSE accuracy of $2.3 \mathrm{~m}(21 \%)$ was obtained in British Columbia, Canada, using a $k$-nearest neighbor $(k$-NN) approach. Mora et al. [26] obtained an RMSE accuracy of $1.95 \mathrm{~m}(11.6 \%)$ for stand height, $9.6 \mathrm{~m}^{3} / \mathrm{ha}$ (12.8\%) for stand volume and 22.2 t/ha (15.8\%) for AGB. In both of these studies, accuracies were reported at the stand level (mean size 9.6 ha in [26]). Mora et al. [25,26] concluded that VHSR and ALS data provide an opportunity for monitoring in areas for which there is no detailed forest inventory information available.

Besides optical images, commercial radar satellite data have rapidly improved in recent years in terms of spatial resolution, thanks to the latest very-high-resolution synthetic aperture radar (SAR) satellites (e.g., TerraSAR-X, COSMO-SkyMed, Radarsat-2, and TanDEM-X). SAR is able to provide images with a resolution of about $1 \mathrm{~m}$ from satellites orbiting at altitudes of several hundreds of kilometers. A major advantage of radar images, compared with optical region satellite images, has been their availability (temporal resolution) under all imaging conditions. This makes radar imaging, especially the SAR approach that is conducted by satellites, an intriguing option in developing methods for operational inventory and monitoring of large areas of forest attributes. Respectively to the optical images, saturation problems also exist with SAR data if the estimation is based solely on the basis of SAR backscatter intensity (e.g., [27]). The saturation level is dependent on the radar wavelength that is used. Perhaps the most promising approach to determining forest attributes by radar imaging is via canopy height information, which is similar to that obtained from ALS. Recent studies have shown that elevation information extracted from stereo SAR data can be used in the estimation of forest attributes, with results emerging that are close to those of ALS data [10,28-31].

There are two approaches to extracting detailed elevation information from SAR images: interferometry and radargrammetry. If the elevation values of the ground surface are accurately known, such as by using an ALS-derived digital terrain model (DTM), then the X-band's or C-band's interferometric or radargrammetric height can be related to the forest canopy height $[5,28,32]$. Radargrammetry is based on the stereoscopic measurement of SAR images (see [33]) in which, analogously to photogrammetric forward intersection, two or more radar images with different viewing perspectives are used to extract 3D information from the target area. Although radargrammetry has 
been a well-known technique for many decades, it has gained new recognition due to recent SAR satellites with enhanced spatial resolution [34]. Interferometric height measurements are based on the phase-differences of two or more SAR data acquisitions with slightly different view angles.

Perko et al. [35] used TerraSAR-X stereo radargrammetry to derive elevation models over forested areas and compared them with ALS data. They concluded that radar-based elevation values correlated with forest canopy height values at the stand level and that the underestimation of the canopy height was dependent on the characteristics of the forest stand. Karjalainen et al. [28] used TerraSAR-X spotlight mode SAR stereo radargrammetry and were able to derive relatively favorable estimates for the mean height and stem volume (the relative RMSE of $34 \%$ for stem volume) at the plot level in Finland's boreal forest zone. Vastaranta et al. [10] evaluated the boreal forest AGB and stem volume prediction accuracy at the plot level when ALS and TerraSAR-X stereo radargrammetry-derived point-height metrics were used as predictors in the NN estimation approach. They obtained a RMSEs of $29.9 \%(41.3 \mathrm{t} / \mathrm{ha})$ and $30.2 \%\left(78.1 \mathrm{~m}^{3} / \mathrm{ha}\right)$ for $\mathrm{AGB}$ and stem volume, respectively, when using radargrammetry-derived metrics. The respective ALS estimation accuracy values were $21.9 \%$ (32.3 t/ha) and 24.8\% (64.2 $\left.\mathrm{m}^{3} / \mathrm{ha}\right)$. Persson and Fransson [32] obtained RMSE of $22.9 \%$ for AGB and $9.4 \%$ for height at the stand level when using TerraSAR-X stereo radargrammetry-derived metrics in the regression modeling. Solberg et al. [29] tested interferometric X-band SAR heights (from the Tandem-X mission) in the estimation of spruce stem volume and AGB. They obtained RMSE values of $43 \%-44 \%$ at the plot level and $19 \%-20 \%$ at the stand level using a nonlinear, mixed model.

The use of TerraSAR-X stereo radargrammetry could be an efficient method for mapping and monitoring forest attributes for large areas if an accurate DTM is available. This study is a continuation of the Karjalainen et al. [28] study, described above, where a basic suite of forest inventory attributes were predicted and validated at the plot level. Our objective is to better understand the strengths and limitations of radargrammetry for estimating forest inventory attributes at the stand level. We used stereo-SAR imagery and radargrammetry to predict forest stands' Lorey's height, basal area, stem volume, and AGB and evaluated the prediction accuracy using ALS-based ABA inventory as a validation data. In addition, we investigated capabilities of radargrammetry in capturing the variation in the most commonly estimated forest attributes and canopy structure. The results obtained with stereo-SAR were also compared to the forest attribute maps provided by Finnish multi-source NFI, which is the current operational large area map source in Finland.

\section{Materials}

\subsection{Study Area and TerraSAR-X Stereoimages}

The study area is located in Espoo-Kirkkonummi, Southern Finland, approximately $20 \mathrm{~km}$ west of the city of Helsinki $\left(60^{\circ} 10^{\prime} \mathrm{N}\right.$ and $24^{\circ} 36^{\prime} \mathrm{E}$, Figure 1$)$. The elevation values (i.e., the heights above the geoid) range from $0 \mathrm{~m}$ to $50 \mathrm{~m}$ above sea level. The Bay of Espoonlahti is located in the middle of the test area. In the present study, four TerraSAR-X (non-interferometric) spotlight mode images acquired at 2009 were used. TerraSAR-X is a modern SAR satellite that is capable of providing images with very high resolution (i.e., approximately $1 \mathrm{~m}$ on the ground at maximum). All images were ordered as multilook ground range detected (MGD) products, in which zero height from WGS84 was used in 
ground range projection. The image set consisted of two same-side stereo pairs from both ascending and descending orbits, suitable for radargrammetric processing. Both stereo pairs have an intersecting angle of about 16 degrees. The accuracy of the stereoscopic measurements of the 3D coordinates using these images was studied in Karjalainen et al. [28] and the results were about $1 \mathrm{~m}$ for well-defined image targets.

Figure 1. The area covered by TerraSAR-X stereoimages. The aerial orthophoto was acquired from the National Land Survey of Finland in March 2013.

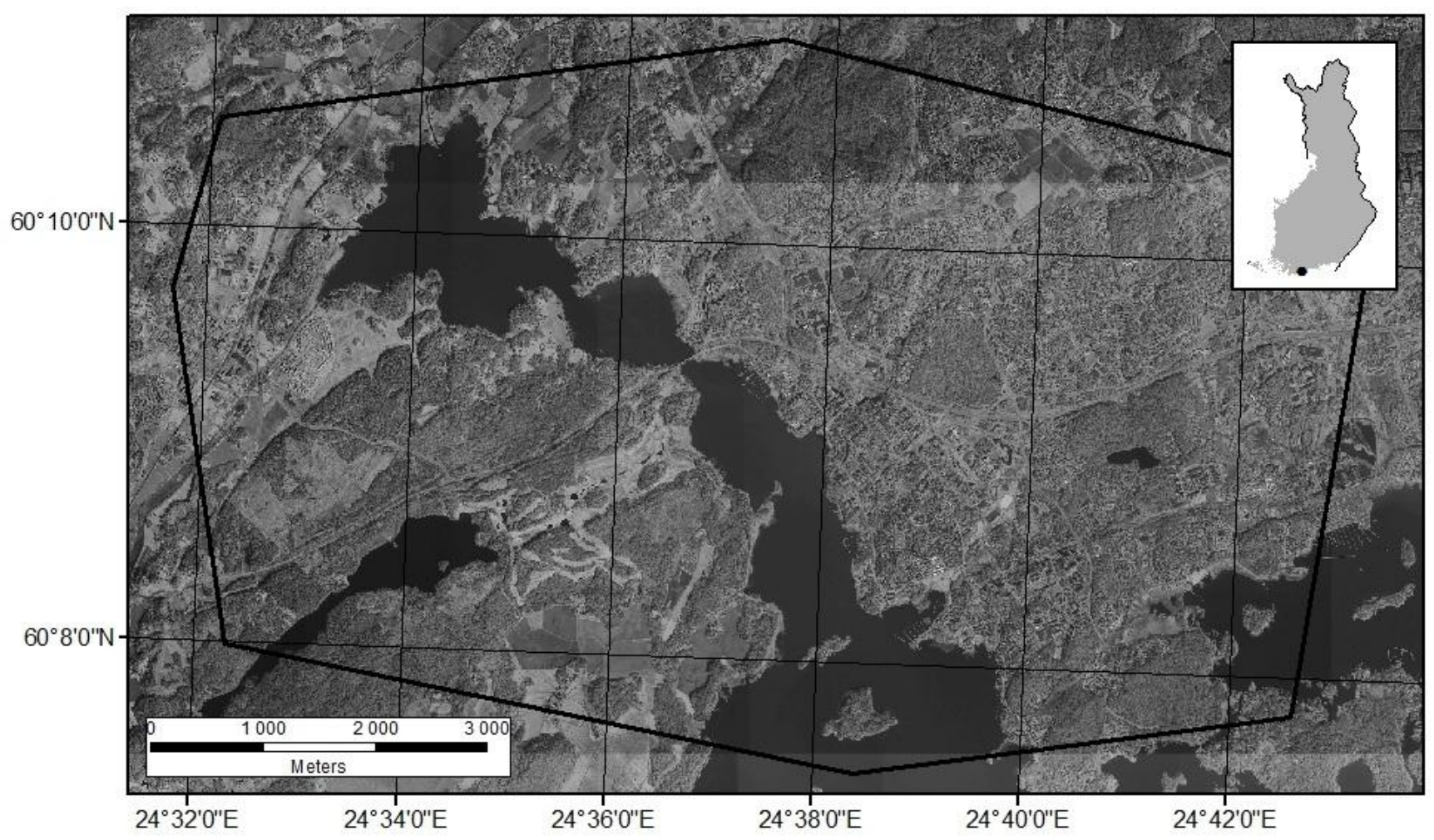

\subsection{Field Measurements}

The field measurement campaigns for 207 plots $(r=8 \mathrm{~m})$ were carried out in autumn of 2010 and supplemented in January of 2013. Selection of the plots was based on the ALS height and density metrics to cover range of different forest structures. All of the plots were located with a handheld global navigation satellite system device (GeoXT 2008, Trimble Navigation Ltd., Sunnyvale, CA, USA) and supported by virtual reference station (VRS) data. In the field, the diameter-at-breast height $(\mathrm{DBH})$ and tree species were determined for all trees with a $\mathrm{DBH}$ of more than $5 \mathrm{~cm}$. In addition, the height of every fifth tree was measured using a Haglöf Vertex clinometer (Haglöf Sweden AB, Långsele, Sweden). Most of the plots were located in conifer-dominated stands.

After the field measurements, the tree heights were modeled for all the trees by fitting Näslund's height-curve [36] to the field-measured height and DBH data. The stem volumes and AGBs were calculated by using tree-level models [37-39]. The models used tree species, DBH, and height as predictors. Plot-level Lorey's height, basal area, AGB, and stem volume estimates were obtained by summing the tree data. Growth of two growing periods was reduced from the plots measured in 2013 to be equivalent with the plots measured in 2010. At the tree-level $\mathrm{DBH}$, growth was $0.2 \mathrm{~cm}$ per year, 
and height growth was $16 \mathrm{~cm}$ per year, on average. Plot-level growth was only $0.1 \mathrm{~m}(0.6 \%)$ per year in Loreys's height, $0.2 \mathrm{~cm}(0.9 \%)$ per year in mean diameter, $0.5 \mathrm{~m}^{2} / \mathrm{ha}(2.2 \%)$ per year in basal area and $4.3 \mathrm{~m}^{3} / \mathrm{ha}(2.2 \%)$ per year in stem volume. Thus, overall, the effect of the growth reduction was marginal. Summary of the calculated forest attributes is presented in Table 1.

Table 1. Summary of the field measures.

\begin{tabular}{ccccc}
\hline & $\begin{array}{c}\text { Lorey's Height } \\
\mathbf{m}\end{array}$ & $\begin{array}{c}\text { Basal Area } \\
\mathbf{m}^{\mathbf{2}} \mathbf{h a}\end{array}$ & $\begin{array}{c}\text { Stem Volume } \\
\mathbf{m}^{\mathbf{3}} / \mathbf{h a}\end{array}$ & $\begin{array}{c}\text { AGB } \\
\mathbf{t} / \mathbf{h a}\end{array}$ \\
\hline min & 5.0 & 2.1 & 6.7 & 3.9 \\
mean & 16.9 & 27.9 & 231.7 & 116.5 \\
max & 25.4 & 69.3 & 712.9 & 347.1 \\
st. dev & 4.1 & 11.5 & 123.2 & 59.7 \\
\hline
\end{tabular}

\subsection{ALS Data and DTM}

The ALS data were acquired by National Land Survey of Finland. The scanning was done in May 2008 with the following parameters: The flying altitude was $\sim 2000 \mathrm{~m}$, and the nominal side overlap between the flight lines was $20 \%$, with a scan angle of 40 degrees, a foot print diameter of $\sim 50 \mathrm{~cm}$ and an average pulse density of 0.5 pulses $/ \mathrm{m}^{2}$. The DTM with $1 \mathrm{~m}$ grid size was generated from last pulse ALS data using the triangular method [40]. The same ALS data used in DTM production were also used in ALS feature extraction (see Section 3.2).

\subsection{Finnish Multi-Source National Forest Inventory}

Finnish multi-source NFI (MS-NFI) produces forest attribute maps that have been used for large area forest management planning and reporting to international conventions [41]. MS-NFI is based on field plot network and Landsat 5 TM or Landsat 7 ETM+ imagery. The sample plots are arranged into clusters, and the distances between clusters are $6 \times 6 \mathrm{~km}$ in the southernmost part of Finland. The spatial information on forest attributes is estimated by a $k$-NN estimation approach with a spatial resolution of $20 \mathrm{~m}$. Here, thematic raster maps of total stem volume, AGB, basal area and Lorey's height from 2009 were used. The stand-level estimates were processed from the 20-m grid maps as the mean value (weighted mean value for Lorey's height).

\section{Methods}

\subsection{Radargrammetric Processing}

The Next-Generation Automatic Terrain Extraction (NGATE) module of Socet Set software by BAE Systems (version 5.5) was used (Bae Systems, London, UK) in the radargrammetric processing of the stereo-SAR imagery. The same-side stereo pairs were used in the automatic image matching. Any combinations of ascending and descending images were omitted from the processing because the automatic tie-point search turned out to be mostly unsuccessful in these cases. In the opposite-side pairs, the target area is seen from the opposite direction; as a result, it is not possible to find tie-points in forested areas that comprise complex structures. Each image pair resulted in a point cloud that 
consisted of 3D coordinates for the successfully located tie-points. The DTM produced by ALS was used to obtain above-ground elevation values for the radargrammetric observations. Further information on radargrammetric processing is given in [28].

\subsection{Feature Extraction from Stereo-SAR and ALS Point Clouds}

To acquire enough 3D points using stereo-SAR data for each test plot, we needed to combine the point clouds of the same-side image pairs, and we had to increase the radius of the feature extraction circle to $20 \mathrm{~m}$. The increase in radius was not a problem because the test plots were selected to be safely located in the middle of a forest stand. There were still 15 test plots that were deleted from the stereo-SAR training data, because the number of stereo-SAR points was less than 10 . The feature extraction circle used with ALS data was $8 \mathrm{~m}$ respective to the field-measured plot.

We extracted features describing vegetation height and density according to Næsset [13] and Junttila et al. [42] from stereo-SAR and ALS points (Table A1). In addition, we calculated transforms like square, square root or logarithm of the feature. In total, we calculated 72 stereo-SAR-derived features and 111 ALS-derived features to be used as preliminary predictors. (Part of the features was calculated separately for the first and the last pulses. See Table A2).

\subsection{Stand Delineation}

Stand delineation was based on vegetation height and density rasters produced from ALS data. The 85th percentile of the observations' height distribution was used as the height raster, and the density raster was derived as the relation of vegetation points to all points. The composed two-channel segmentation raster was filtered by median filtering and mean-shift filtering [43] to make uniform areas but preserve stand borders.

The stands were delineated by limited iterative region-growing algorithm presented by [44]. We calculated the stand-level estimation accuracy for those stands containing at least one reference plot. In the analysis, we had 94 stands ranging from 0.5 ha to 12.2 ha, with an average size of 4.1 ha and median size of 3.3 ha.

\subsection{Forest Attribute Predictions and Generation of Stand Level Attributes}

Forest attributes were predicted for grids inside the stands by $k$-Most Similar Neighbor (MSN) method $[45,46]$. The grid size corresponded to the size of the feature extraction unit: stereo-SAR predictions were generated to $35 \mathrm{~m}$ grid and ALS results to $14 \mathrm{~m}$ grid. The mixed pixels at the edge of the stands with an area of less than half of the original pixel size were merged with neighboring pixels.

First, the number of predictors was decreased by investigating their relation to the forest attributes, and then predictors that have a weak correlation with forest attributes were removed. Then, we sought the best explanatory predictors of the stem volume by building a multiple linear regression model and limiting the number of features by stepwise selection using $\mathrm{R}$ statistical software [47]. The final predictors were selected by testing the different predictor combinations in $k$-MSN estimation and choosing the predictor set, which gave the best estimation accuracy of forest stem volume. The selected features are presented in Table A1. We used one to five most similar reference plots for every 
pixel, and the grid-level forest attributes were derived as the neighbors' Mahalanobis distance (See [45]) weighted average of the forest attributes. Stand-level forest attributes were estimated as the average values of grid-level attributes inside the stands. The variation in stand-level forest attributes derived using ALS-based ABA are presented in Table 2.

Table 2. The stand attributes predicted using airborne laser scanning (ALS) data.

\begin{tabular}{ccccc}
\hline & $\begin{array}{c}\text { Lorey's Height } \\
\mathbf{m}\end{array}$ & $\begin{array}{c}\text { Basal Area } \\
\mathbf{m}^{\mathbf{2}} / \mathbf{h a}\end{array}$ & $\begin{array}{c}\text { Stem Volume } \\
\mathbf{m}^{\mathbf{3}} / \mathbf{h a}\end{array}$ & $\begin{array}{c}\text { AGB } \\
\mathbf{t} / \mathbf{h a}\end{array}$ \\
\hline $\min$ & 10.0 & 12.6 & 69.0 & 37.1 \\
$\operatorname{mean}$ & 15.6 & 24.4 & 191.0 & 96.4 \\
$\max$ & 20.9 & 37.8 & 355.0 & 176.0 \\
st. dev & 2.7 & 6.0 & 68.7 & 33.2 \\
\hline
\end{tabular}

\subsection{Accuracy Evaluation}

A cross-validation procedure was applied in the accuracy evaluation. The plots inside the stand that was predicted were excluded from the training data, and this was repeated until all stands were predicted. The accuracy of the predicted stand attributes was evaluated by calculating bias and RMSE by comparing stereo-SAR and MS-NFI predictions to the ALS counterparts:

$$
\begin{gathered}
B I A S=\frac{\sum_{i=1}^{n}\left(y_{i}-\hat{y}_{i}\right)}{n} \\
R M S E=\sqrt{\frac{\sum_{i=1}^{n}\left(y_{i}-\hat{y}_{i}\right)^{2}}{n}}
\end{gathered}
$$

where $n$ is the number of stands, $y_{i}$ the value estimated from the ALS data for stand $i, \hat{y}_{i}$ the predicted value for stand $i$. The relative bias and RMSE were calculated according to the sampled mean of the variable in question.

\section{Results}

\subsection{Comparison of Radargrammetric, ALS and Field Measures at the Plot Level}

ALS and stereo-SAR maximum heights were highly correlated at the plot level $(r=0.69)$ (Figure 2). ALS and stereo-SAR 85th height percentiles were also correlated with Lorey's height (Figure 3). The correlations' coefficients were 0.88 and 0.61 for ALS and stereo-SAR, respectively. However, the canopy cover percentages, at the height of $25 \%$ to $75 \%$, show that stereo-SAR points are concentrated to the higher canopy layers, as ALS is more capable of capturing the entire range of canopy height variation (Figure 2). At $75 \%$ of height, at least $70 \%$ of ALS observations are returns from lower canopy layers as there are already many plots without any Stereo-SAR observations below that height. In addition, vegetation density (see Table A2) calculated from ALS point heights was $60 \%$, as it was 94\% in stereo-SAR data, indicating that ALS captures more small canopy openings than stereo-SAR. Stereo-SAR was capable of providing ground observations or close to ground observations $(<1 \mathrm{~m})$ in forested areas in $70.4 \%$ of the plots where stem volume was below $100 \mathrm{~m}^{3} /$ ha. The percentage of the 
plots having ground observation decreased rapidly when the amount of stem volume increased. Only $29.8 \%$ of the plots included ground observations when the stem volume was between $200 \mathrm{~m}^{3} / \mathrm{ha}$ and $300 \mathrm{~m}^{3} /$ ha (Figure 4).

Figure 2. Plot-level maximum point heights and proportions of the points below a $25 \%$, $50 \%$ and $75 \%$ given percentage of the maximum ALS height $(25,50$, and 75 percentage).
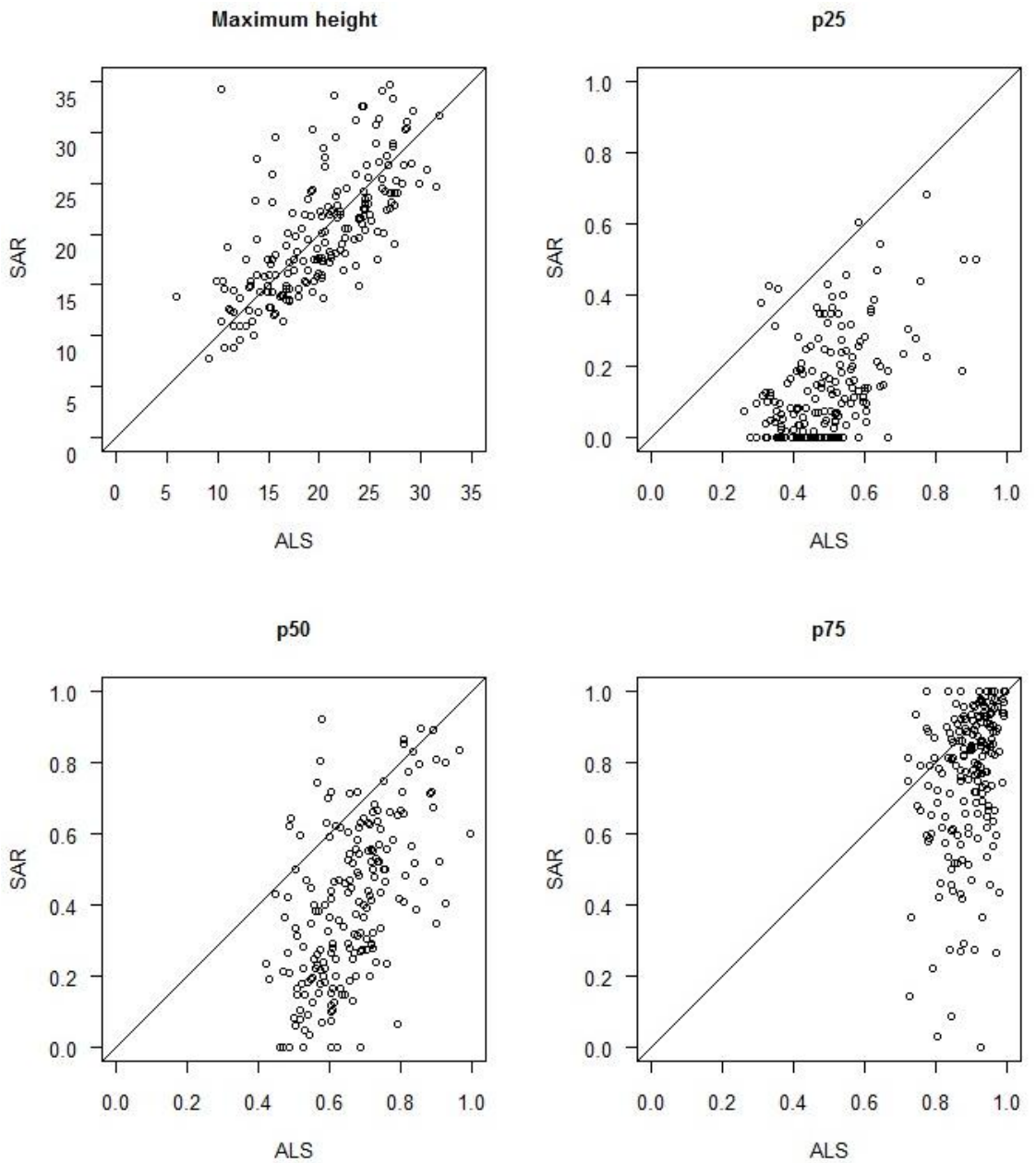

Figure 3. The 85th percentile (h85) of the ALS and SAR points related to observed Lorey's height at the plot level.
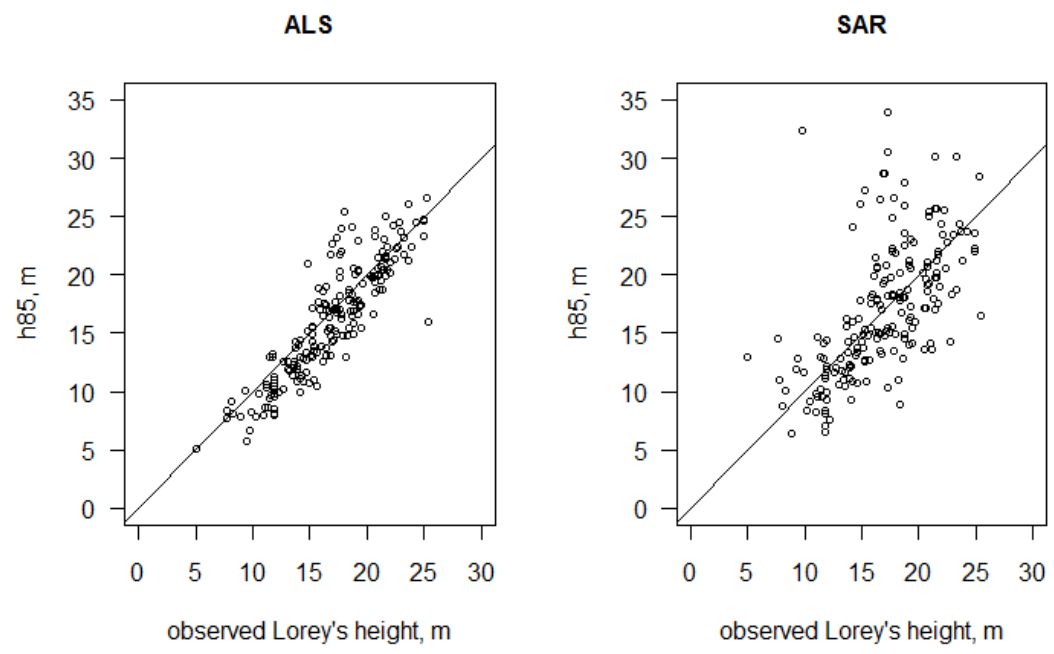
Figure 4. Vegetation density based on ALS and SAR related to observed stem volume at the plot level.

ALS

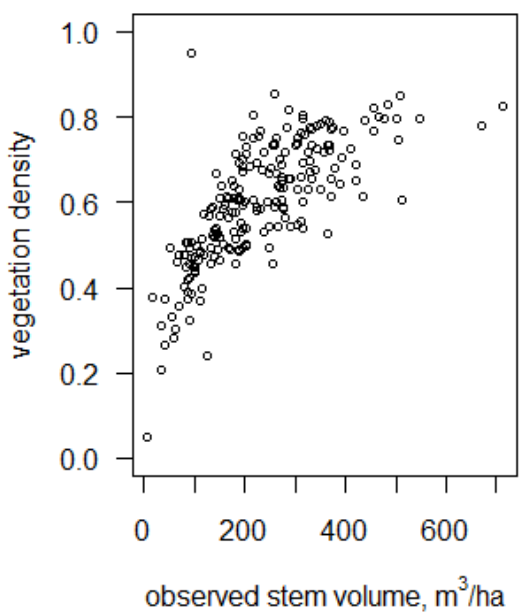

SAR

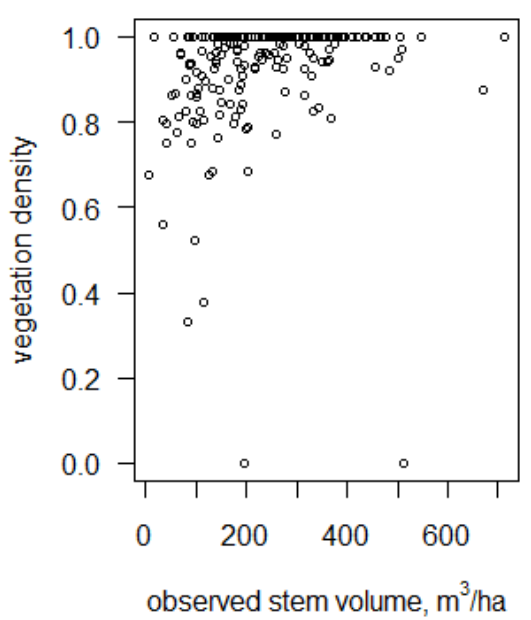

\subsection{Stand Level Accuracy Evaluation}

Lorey's height was the most accurately predicted stand attribute (Table 3). RMSEs ranged from $6.7 \%$ to $7.8 \%$. Predictions were overestimations (between $-4.6 \%$ and $-5.2 \%$ ). Stereo-SAR outperformed MS-NFI results that had an RMSE of $16.0 \%$ and bias of $-12.6 \%$.

Table 3. Stand-level estimation accuracy of Lorey's height by stereo-SAR and multi-source national forest inventory (NFI).

\begin{tabular}{cccccc}
\hline Method & k & Bias $(\mathbf{m})$ & Bias \% & RMSE $(\mathbf{m})$ & RMSE \% \\
\hline Stereo-SAR & 1 & -0.8 & -4.9 & 1.3 & 7.8 \\
Stereo-SAR & 2 & -0.8 & -4.9 & 1.1 & 7.1 \\
Stereo-SAR & 3 & -0.8 & -5.2 & 1.2 & 7.3 \\
Stereo-SAR & 4 & -0.8 & -5.0 & 1.1 & 7.1 \\
Stereo-SAR & 5 & -0.7 & -4.6 & 1.1 & 6.7 \\
Multi-source NFI & & -2.0 & -12.6 & 2.6 & 16.0 \\
\hline
\end{tabular}

Table 4. Stand-level estimation accuracy of forest basal area by stereo-SAR and multi-source NFI.

\begin{tabular}{cccccc}
\hline Method & $\mathbf{k}$ & $\begin{array}{c}\text { Bias } \\
\left(\mathbf{m}^{\mathbf{2}} \mathbf{h a}\right)\end{array}$ & Bias \% & $\begin{array}{c}\text { RMSE } \\
\left(\mathbf{m}^{\mathbf{2}} \mathbf{h a}\right)\end{array}$ & RMSE \% \\
\hline Stereo-SAR & 1 & -1.6 & -6.4 & 2.9 & 12.0 \\
Stereo-SAR & 2 & -2.1 & -8.4 & 3.0 & 12.3 \\
Stereo-SAR & 3 & -2.3 & -9.3 & 3.0 & 12.5 \\
Stereo-SAR & 4 & -2.2 & -8.9 & 3.0 & 12.1 \\
Stereo-SAR & 5 & -2.2 & -9.0 & 2.9 & 12.0 \\
Multi-source NFI & & 5.1 & 20.8 & 6.6 & 26.9 \\
\hline
\end{tabular}


Predictions for basal area, stem volume and AGB were also clearly more accurate with stereo-SAR than MS-NFI (Tables 4-6). Stereo-SAR predictions were overestimations for the basal area (-6.4\% to $-9.3 \%)$, stem volume ( $-9.3 \%$ to $-13.4 \%)$ and AGB $(-9.5 \%$ to $-13.2 \%)$. The MS-NFI basal area was underestimated by $20.8 \%$, and stem volume was underestimated by $10.5 \%$. The MS-NFI-based AGB was only slightly overestimated $(-1.2 \%)$. It can be seen from Figure 5 that stereo-SAR-derived stem volume predictions are not saturating as MS-NFI stem volumes. MS-NFI predictions for stands with stem volume of over $200 \mathrm{~m}^{3} /$ ha are all underestimated.

Table 5. Stand-level estimation accuracy of forest volume by stereo-SAR and multi-source NFI.

\begin{tabular}{cccccc}
\hline Method & $\mathbf{k}$ & $\begin{array}{c}\text { Bias } \\
\left(\mathbf{m}^{\mathbf{3}} \mathbf{h a}\right)\end{array}$ & Bias \% & RMSE (m $\mathbf{3} / \mathbf{h a})$ & RMSE \% \\
\hline Stereo-SAR & 1 & -17.8 & -9.3 & 31.1 & 16.3 \\
Stereo-SAR & 2 & -23.1 & -12.1 & 32.5 & 17.0 \\
Stereo-SAR & 3 & -25.6 & -13.4 & 33.9 & 17.7 \\
Stereo-SAR & 4 & -24.9 & -13.1 & 33.1 & 17.3 \\
Stereo-SAR & 5 & -24.5 & -12.8 & 32.5 & 17.0 \\
Multi-source NFI & & 20.0 & 10.5 & 49.4 & 25.8 \\
\hline
\end{tabular}

Table 6. Stand-level estimation accuracy of forest above-ground biomass (AGB) by stereo-SAR radargrammetry and multi-source NFI.

\begin{tabular}{cccccc}
\hline Method & k & Bias (t/ha) & Bias \% & RMSE (t/ha) & RMSE \% \\
\hline Stereo-SAR & 1 & -9.1 & -9.5 & 15.6 & 16.1 \\
Stereo-SAR & 2 & -11.7 & -12.2 & 16.1 & 16.7 \\
Stereo-SAR & 3 & -12.8 & -13.2 & 16.7 & 17.3 \\
Stereo-SAR & 4 & -12.5 & -12.9 & 16.4 & 17.0 \\
Stereo-SAR & 5 & -12.2 & -12.7 & 16.1 & 16.7 \\
Multi-source NFI & & -1.2 & -1.2 & 21.7 & 22.5 \\
\hline
\end{tabular}

Figure 5. Stand-level stem volume estimates by stereo-SAR and multi-source NFI related to area-based ALS interpretation.

SAR

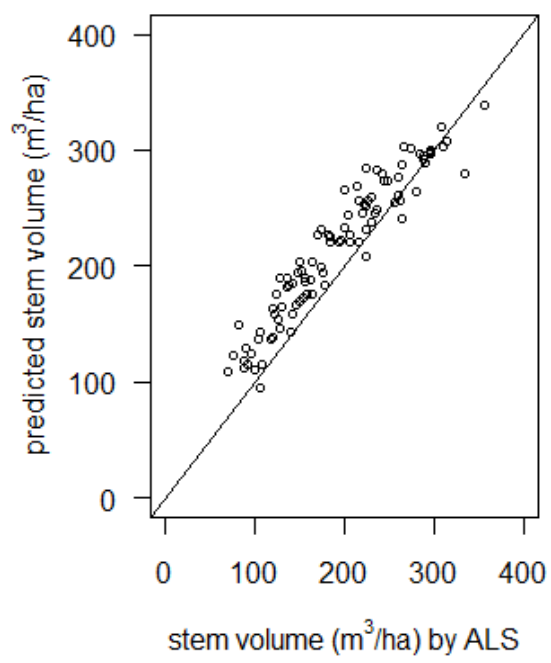

MS-NFI

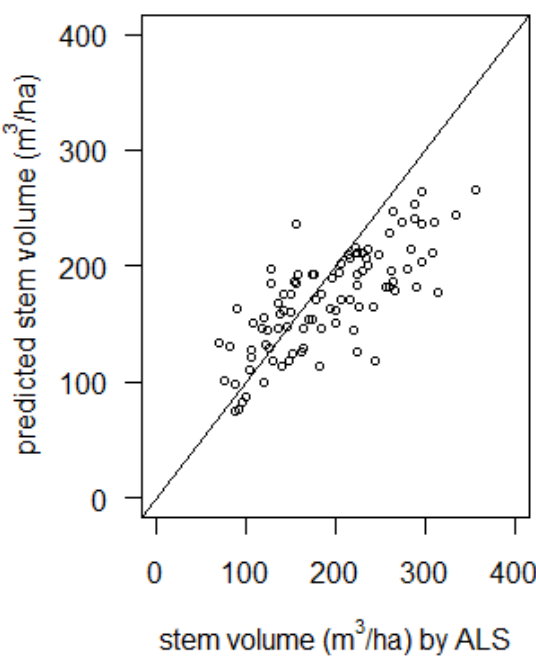




\section{Discussion}

Stereo-SAR is capable of producing 3D metrics that can be used in the mapping of forest stand attributes. Stereo-SAR is especially suitable for mapping of forest height-related variables, such as Lorey's height, which was predicted here. It should be noted, however, that stereo-SAR requires a spatially detailed DTM to normalize obtained heights to heights above ground level. However, as stereo-SAR-derived elevations appear to be linearly correlated with forest height, it could be possible to detect forest biomass changes even without the existing DTM [29]. With ALS-derived DTM, stereo-SAR-based predictions of Lorey's height, basal area, stem volume and AGB were more accurate than results obtained with MS-NFI. Stand-level prediction accuracies were also in line or even slightly better than obtained in stand-wise field inventories based on relascope measurements $[15,48]$. Overall, the performance of stereo-SAR in the prediction of forest stand attributes would be promising for large-area monitoring applications, but we remain circumspect on recommendations regarding the use of stereo-SAR because the predictions were biased. The source of bias was investigated, and several factors may have contributed. Part of the bias stems from stereo-SARs' limited capability to detect the small canopy openings. For example, ALS-based vegetation density, which is highly correlated with canopy cover, was $60 \%$ on average in our evaluation stands, as it was $94 \%$ based on stereo-SAR. When canopy openings are not detected, basal area, stem volume and AGB are overestimated. The variation in our plot-level training should have represented the validation stands as well as possible because our predictions were validated only in those stands that included at least one training plot. However, less vegetated areas in our test stands were included than in our training data. The vegetation density was on average $52 \%$ in our study area, based on ALS. However, the respective mean value in our training plots was $60 \%$, meaning that our training plots were located in denser forests than average. In addition, the vegetation density was below $20 \%$ in areas covering $5 \%$ of the validation area, as only one training plot was located in such a sparsely vegetated stand. In addition, the number of the used neighbors also clearly affected the amount of bias. The lowest biases were always obtained with a $k$ value of one.

ALS-based predictions provided the stand-level validation data, and it should be noted that those predictions include also estimation error. At the stand level, accuracy of the ALS-based forest inventory is expected to vary between RMSE of 5\% and 10\% in stem volume, basal area and Lorey's height $[46,49]$. Our comparison to the MS-NFI should be carefully interpreted. ALS-based predictions provided the validation data, and those were based on the same field plot data that were used with stereo-SAR. Naturally, this procedure favored stereo-SAR. Nevertheless, MS-NFI could not predict stem volumes of over $300 \mathrm{~m}^{3} / \mathrm{ha}$. Stereo-SAR saturation was not detected, and, in general, this is the major advantage of all 3D methods (e.g., [50]).

We obtained an RMSE accuracy of 7.0\% $(1.1 \mathrm{~m})$ for Lorey's height. The prediction accuracy is close to accuracies obtained using ALS data, which are $\sim 1 \mathrm{~m}$ (e.g., [10,51,52]). When ALS has been used for calibration of forest characteristic predictions using medium resolution optical satellite imagery (for example, Landsat images), stand height prediction RMSE accuracy drops to between two and three meters [22,23,25]. With high resolution IKONOS imagery, obtained height prediction accuracies have also been $\sim 3 \mathrm{~m}$ (e.g., [53]). Thus, it can be concluded that radargrammetry appears to be a suitable method for mapping of stand height over large areas. Stereo-SAR-based predictions for 
basal area and stem volume were also more accurate compared to respective predictions by Peuhkurinen et al. [53] using IKONOS imagery validated using approximately same sized stands. Stereo-SAR-based prediction RMSE accuracies were $12.0 \%$ and $16.3 \%$ for basal area and stem volume, and the respective accuracies using IKONOS imagery were $25.3 \%$ and 31.3\%. Mora et al. [26] obtained similar accuracies for forest stand attributes, but results were validated using larger stands (9.6 ha). Stand size has a notable effect on the accuracy of the remote sensing-based forest inventory [54]. Mainly, there are two approaches to extracting detailed elevation information from SAR images. Thus, it is intriguing to compare results obtained with interferometry and radargrammetry. Solberg et al. [29] predicted spruce stem volume and AGB using an interferometric-derived digital surface model. The obtained stand level prediction accuracies were slightly imprecise, considering the RMSE percentages (19\%-20\% for stem volume and AGB). Respective results were obtained by Persson and Fransson [32] for AGB (also for height) with radargrammetry in Sweden.

Based on these results, the accuracy level that can be obtained by means of stereo-SAR seems slightly worse than can be obtained using low density $\left(<1\right.$ pulse $\left./ \mathrm{m}^{2}\right)$ ALS data [10] or digital stereo imagery derived DSM [55,56], but is far more accurate than can be obtained with 2D methodologies [2-4,27,53]. Thus, if large areas can be first covered with ALS to produce detailed DTMs, stereo-SAR can be used to provide consistent forest maps or detailed forest monitoring.

\section{Conclusions}

The accuracy level that can be obtained by means of stereo-SAR in prediction of forest stand attributes is much greater than the accuracy that can be obtained using $2 \mathrm{D}$ remote-sensing data. One caveat associated with the use of stereo-SAR is the requirement for a spatially detailed DTM to normalize obtained heights to heights above ground level. With detailed DTM, TerraSAR-X stereo radargrammetry-derived forest information appears to be suitable for providing consistent forest attribute maps over large areas.

\section{Acknowledgments}

The research leading to these results has received funding from the European Community's Seventh Framework Programme ([FP7/2007-2013]) under grant agreement $n^{\circ}$ 606971. The Academy of Finland is acknowledged as well for its financial support in the form of the Science and Technology Towards Precision Forestry project and Centre of Excellence in Laser Scanning Research (CoE-LaSR). The TerraSAR-X imagery was acquired through the German Aerospace Center (DLR) prelaunch Announcement of Opportunity scientific project (LAN-0049). The authors wish to use this opportunity to express their appreciation to DLR for the image data.

\section{Conflicts of Interest}

The authors declare no conflicts of interest. 


\section{References}

1. Tomppo, E.O.; Schadauer, K. Harmonization of national forest inventories in Europe: Advances under COST action E43. For. Sci. 2012, 58, 191-200.

2. Tuominen, S.; Haakana, M. Landsat TM imagery and high altitude aerial photographs in estimation of forest characteristics. Silva Fenn. 2005, 39, 573-584.

3. Franco-Lopez, H.; Ek, A.R.; Bauer, M.E. Estimation and mapping of forest stand density, volume, and cover type using the $k$-nearest neighbors method. Remote Sens. Environ. 2001, 77, 251-274.

4. Holmstrom, H.; Fransson, J.E. Combining remotely sensed optical and radar data in kNN-estimation of forest variables. For. Sci. 2003, 49, 409-418.

5. Kellndorfer, J.M.; Walker, W.; LaPoint, E.; Kirsch, K.; Bishop, J.; Fiske, G. Statistical fusion of Lidar, InSAR, and optical remote sensing data for forest stand height characterization: A regional-scale method based on LVIS, SRTM, Landsat ETM+, and ancillary data sets. J. Geophys. Res. Biogeosciences 2010, 115, doi:10.1029/2009JG000997.

6. Lefsky, M.A.; Harding, D.; Cohen, W.; Parker, G.; Shugart, H. Surface lidar remote sensing of basal area and biomass in deciduous forests of eastern Maryland, USA. Remote Sens. Environ. 1999, 67, 83-98.

7. Lim, K.S.; Treitz, P.M. Estimation of above ground forest biomass from airborne discrete return laser scanner data using canopy-based quantile estimators. Scand. J. For. Res 2004, 19, 558-570.

8. Nelson, R.; Krabill, W.; Tonelli, J. Estimating forest biomass and volume using airborne laser data. Remote Sens. Environ. 1988, 24, 247-267.

9. Van Aardt, J.A.; Wynne, R.H.; Oderwald, R.G. Forest volume and biomass estimation using small-footprint lidar-distributional parameters on a per-segment basis. For. Sci. 2006, 52, 636-649.

10. Vastaranta, M.; Holopainen, M.; Karjalainen, M.; Kankare, V.; Hyyppa, J.; Kaasalainen, S. TerraSAR-X stereo radargrammetry and airborne scanning LiDAR height metrics in imputation of forest aboveground biomass and stem volume. IEEE Trans. Geosci. Remote Sens. 2014, 52, 1197-1204.

11. Kankare, V.; Vastaranta, M.; Holopainen, M.; Räty, M.; Yu, X.; Hyyppä, J.; Hyyppä, H.; Alho, P.; Viitala, R. Retrieval of forest aboveground biomass and stem volume with airborne scanning LiDAR. Remote Sens. 2013, 5, 2257-2274.

12. Næsset, E. Practical large-scale forest stand inventory using a small-footprint airborne scanning laser. Scand. J. For. Res. 2004, 19, 164-179.

13. Næsset, E. Predicting forest stand characteristics with airborne scanning laser using a practical two-stage procedure and field data. Remote Sens. Environ. 2002, 80, 88-99.

14. Næsset, E.; Gobakken, T.; Holmgren, J.; Hyyppä, H.; Hyyppä, J.; Maltamo, M.; Nilsson, M.; Olsson, H.; Persson, Å.; Söderman, U. Laser scanning of forest resources: The Nordic experience. Scand. J. For. Res. 2004, 19, 482-499.

15. Holopainen, M.; Vastaranta, M.; Rasinmäki, J.; Kalliovirta, J.; Mäkinen, A.; Haapanen, R.; Melkas, T.; Yu, X.; Hyyppä, J. Uncertainty in timber assortment estimates predicted from forest inventory data. Eur. J. For. Res. 2010, 129, 1131-1142. 
16. Asner, G.P.; Powell, G.V.; Mascaro, J.; Knapp, D.E.; Clark, J.K.; Jacobson, J.; Kennedy-Bowdoin, T.; Balaji, A.; Paez-Acosta, G.; Victoria, E. High-resolution forest carbon stocks and emissions in the Amazon. Proc. Natl. Acad. Sci. 2010, 107, 16738-16742.

17. Andersen, H.-E.; Strunk, J.; Temesgen, H. Using airborne light detection and ranging as a sampling tool for estimating forest biomass resources in the Upper Tanana Valley of Interior Alaska. West. J. Appl. For. 2011, 26, 157-164.

18. Gregoire, T.G.; Ståhl, G.; Næsset, E.; Gobakken, T.; Nelson, R.; Holm, S. Model-assisted estimation of biomass in a LiDAR sample survey in Hedmark County, Norway. Can. J. For. Res. 2010, 41, 83-95.

19. Ståhl, G.; Holm, S.; Gregoire, T.G.; Gobakken, T.; Næsset, E.; Nelson, R. Model-based inference for biomass estimation in a LiDAR sample survey in Hedmark County, Norway. Can. J. For. Res. 2010, 41, 96-107.

20. Gobakken, T.; Næsset, E.; Nelson, R.; Bollandsås, O.M.; Gregoire, T.G.; Ståhl, G.; Holm, S.; Ørka, H.O.; Astrup, R. Estimating biomass in Hedmark County, Norway using national forest inventory field plots and airborne laser scanning. Remote Sens. Environ. 2012, 123, 443-456.

21. Wulder, M.A.; White, J.C.; Bater, C.W.; Coops, N.C.; Hopkinson, C.; Chen, G. Lidar plots-A new large-area data collection option: Context, concepts, and case study. Can. J. Remote Sens. 2012, 38, 600-618.

22. Maselli, F.; Chiesi, M.; Montaghi, A.; Pranzini, E. Use of ETM+ images to extend stem volume estimates obtained from LiDAR data. ISPRS J. Photogramm. Remote Sens. 2011, 66, 662-671.

23. Wulder, M.A.; Seemann, D. Forest inventory height update through the integration of lidar data with segmented Landsat imagery. Can. J. Remote Sens. 2003, 29, 536-543.

24. Chen, G.; Wulder, M.A.; White, J.C.; Hilker, T.; Coops, N.C. Lidar calibration and validation for geometric-optical modeling with Landsat imagery. Remote Sens. Environ. 2012, 124, 384-393.

25. Mora, B.; Wulder, M.A.; Hobart, G.W.; White, J.C.; Bater, C.W.; Gougeon, F.A.; Varhola, A.; Coops, N.C. Forest inventory stand height estimates from very high spatial resolution satellite imagery calibrated with lidar plots. Int. J. Remote Sens. 2013, 34, 4406-4424.

26. Mora, B.; Wulder, M.A.; White, J.C.; Hobart, G. Modeling stand height, volume, and biomass from very high spatial resolution satellite imagery and samples of airborne LiDAR. Remote Sens. 2013, 5, 2308-2326.

27. Holopainen, M.; Haapanen, R.; Karjalainen, M.; Vastaranta, M.; Hyyppä, J.; Yu, X.; Tuominen, S.; Hyyppä, H. Comparing accuracy of airborne laser scanning and TerraSAR-X radar images in the estimation of plot-level forest variables. Remote Sens. 2010, 2, 432-445.

28. Karjalainen, M.; Kankare, V.; Vastaranta, M.; Holopainen, M.; Hyyppä, J. Prediction of plot-level forest variables using TerraSAR-X stereo SAR data. Remote Sens. Environ. 2012, 117, 338-347.

29. Solberg, S.; Astrup, R.; Breidenbach, J.; Nilsen, B.; Weydahl, D. Monitoring spruce volume and biomass with InSAR data from TanDEM-X. Remote Sens. Environ. 2013, 139, 60-67.

30. Solberg, S.; Astrup, R.; Weydahl, D.J. Detection of forest clear-cuts with Shuttle Radar Topography Mission (SRTM) and Tandem-X InSAR data. Remote Sens. 2013, 5, 5449-5462. 
31. Vastaranta, M.; Holopainen, M.; Karjalainen, M.; Kankare, V.; Hyyppa, J.; Kaasalainen, S.; Hyyppa, H. SAR Radargrammetry and Scanning LiDAR in Predicting Forest Canopy Height. In Proceedings of the 2012 IEEE International Geoscience and Remote Sensing Symposium (IGARSS), Munich, Germany, 22-27 July 2012; pp. 6515-6518.

32. Persson, H.; Fransson, J.E. Forest variable estimation using radargrammetric processing of TerraSAR-X images in boreal forests. Remote Sens. 2014, 6, 2084-2107.

33. Leberl, F. Accuracy analysis of stereo side-looking radar. Photogramm. Eng. Remote Sens. 1979, 45, 1083-1096.

34. Raggam, H.; Gutjahr, K.; Perko, R.; Schardt, M. Assessment of the stereo-radargrammetric mapping potential of TerraSAR-X multibeam spotlight data. Geosci. Remote Sens. IEEE Trans. 2010, 48, 971-977.

35. Perko, R.; Raggam, H.; Deutscher, J.; Gutjahr, K.; Schardt, M. Forest assessment using high resolution SAR data in X-band. Remote Sens. 2011, 3, 792-815.

36. Näslund, M. Skogsförsöksanstaltens gallringsförsök i tallskog. Medd. Från Statens Skogsförsöksanst. 1936, 29, 1-170.

37. Laasasenaho, J. Taper curve and volume functions for pine, spruce and birch [Pinus sylvestris, Picea abies, Betula pendula, Betula pubescens]. Commun. Inst. For. Fenn. 1982, 108, 1-74.

38. Repola, J. Biomass equations for birch in Finland. Silva Fenn. 2008, 42, 605-624.

39. Repola, J. Biomass equations for Scots pine and Norway spruce in Finland. Silva Fenn. 2009, 43, 625-647.

40. Axelsson, P. DEM generation from laser scanner data using adaptive TIN models. Int. Arch. Photogramm. Remote Sens. 2000, 33, 111-118.

41. Tomppo, E.; Haakana, M.; Katila, M.; Peräsaari, J. Multi-source National Forest Inventory: Methods and Applications; Springer: New York, NY, USA, 2008; Volume 18.

42. Junttila, V.; Kauranne, T.; Leppanen, V. Estimation of forest stand parameters from airborne laser scanning using calibrated plot databases. For. Sci. 2010, 56, 257-270.

43. Comaniciu, D.; Meer, P. Mean shift: A robust approach toward feature space analysis. IEEE Trans. Pattern Anal. Mach. Intell. 2002, 24, 603-619.

44. Leppänen, V.; Tokola, T.; Maltamo, M.; Mehtätalo, L.; Pusa, T.; Mustonen, J. Automatic Delineation of Forest Stands from LIDAR Data. In Proceedings of GEOBIA, Calgary, AB, Canada, 5-8 August 2008.

45. Moeur, M.; Stage, A.R. Most similar neighbor: An improved sampling inference procedure for natural resource planning. For. Sci. 1995, 41, 337-359.

46. Packalén, P.; Maltamo, M. The k-MSN method for the prediction of species-specific stand attributes using airborne laser scanning and aerial photographs. Remote Sens. Environ. 2007, 109, 328-341.

47. R Core Team. R: A Language and Environment for Statistical Computing. Vienna, Austria, 2013. Available online: http://www.R-project.org (accessed on 9 April 2014).

48. Vastaranta, M.; Ojansuu, R.; Holopainen, M. Puustotunnusten laskennallisen ajantasaistuksen luotettavuus-tapaustutkimus Pohjois-Savossa. Metsätieteen Aikakauskirja 2010, 4, 367-381. 
49. Wallenius, T.; Laamanen, R.; Peuhkurinen, J.; Mehtätalo, L.; Kangas, A. Analysing the agreement between an airborne laser scanning based forest inventory and a control inventory-A case study in the state owned forests in Finland. Silva Fenn. 2012, 46, 111-129.

50. Vastaranta, M. Forest mapping and monitoring using active 3D remote sensing. Diss. For. 2012, $144,1-45$.

51. Vastaranta, M.; Kankare, V.; Holopainen, M.; Yu, X.; Hyyppä, J.; Hyyppä, H. Combination of individual tree detection and area-based approach in imputation of forest variables using airborne laser data. ISPRS J. Photogramm. Remote Sens. 2012, 67, 73-79.

52. Maltamo, M.; Eerikäinen, K.; Packalén, P.; Hyyppä, J. Estimation of stem volume using laser scanning-based canopy height metrics. Forestry 2006, 79, 217-229.

53. Peuhkurinen, J.; Maltamo, M.; Vesa, L.; Packalén, P. Estimation of forest stand characteristics using spectral histograms derived from an Ikonos Satellite Image. Photogramm. Eng. Remote Sens. 2008, 74, 1335-1341.

54. Нyyppa, H.; Нyyppa, J. Effects of stand size on the accuracy of remote sensing-based forest inventory. IEEE Trans. Geosci. Remote Sens. 2001, 39, 2613-2621.

55. Bohlin, J.; Wallerman, J.; Fransson, J.E. Forest variable estimation using photogrammetric matching of digital aerial images in combination with a high-resolution DEM. Scand. J. For. Res. 2012, 27, 692-699.

56. Vastaranta, M.; Wulder, M.A.; White, J.C.; Pekkarinen, A.; Tuominen, S.; Ginzler, C.; Kankare, V.; Holopainen, M.; Hyyppä, J.; Hyyppä, H. Airborne laser scanning and digital stereo imagery measures of forest structure: Comparative results and implications to forest mapping and inventory update. Can. J. Remote Sens. 2013, 39, 1-14.

\section{Appendix}

Table A1. ALS- and SAR-derived features, and minimum, maximum, range, mean and standard deviation of the values. The abbreviations are explained in Table A2. The ALS and stereo-SAR features used in the predictions are marked with * and **, respectively.

\begin{tabular}{cccccc|ccccc}
\hline \multicolumn{7}{c|}{ ALS Features } & \multicolumn{5}{c}{ Stereo-SAR Features } \\
\hline & min & max & range & mean & std.dev & min & max & range & mean & std.dev \\
\hline VD* & 0.05 & 0.95 & 0.9 & 0.6 & 0.14 & 0.38 & 1 & 0.62 & 0.94 & 0.1 \\
h85 & 2.6 & 26.95 & 24.35 & 16.05 & 5.34 & 6.43 & 33.96 & 27.53 & 17.01 & 5.61 \\
HV_mean & 0 & 24.29 & 24.29 & 13.14 & 4.53 & 6.12 & 26.93 & 20.81 & 12.82 & 3.87 \\
HV_SD & 0.59 & 11.11 & 10.52 & 5.36 & 1.88 & 0.98 & 9.81 & 8.82 & 4.49 & 1.61 \\
GR2_First & 0 & 0.95 & 0.95 & 0.21 & 0.17 & 0 & 0.62 & 0.62 & 0.06 & 0.1 \\
GR2_Last & 0.08 & 1 & 0.92 & 0.65 & 0.22 & - & - & - & - & - \\
GR5_First*** & 0 & 1 & 1 & 0.27 & 0.21 & 0 & 0.83 & 0.83 & 0.17 & 0.19 \\
GR5_Last & 0.2 & 1 & 0.8 & 0.69 & 0.21 & - & - & - & - & - \\
GR7_First & 0 & 1 & 1 & 0.34 & 0.26 & 0 & 0.98 & 0.98 & 0.26 & 0.26 \\
GR7_Last* & 0.21 & 1 & 0.79 & 0.72 & 0.21 & - & - & - & - & - \\
L_3.5 & 0.01 & 0.99 & 0.98 & 0.65 & 0.22 & 0 & 0.56 & 0.56 & 0.05 & 0.08 \\
L_5.5 & 0.17 & 1 & 0.83 & 0.67 & 0.22 & 0 & 0.73 & 0.73 & 0.11 & 0.14 \\
L_7.5 & 0.2 & 1 & 0.8 & 0.7 & 0.21 & 0 & 0.85 & 0.85 & 0.19 & 0.22 \\
L_9.5 & 0.23 & 1 & 0.77 & 0.72 & 0.21 & 0 & 0.98 & 0.98 & 0.29 & 0.27 \\
\hline
\end{tabular}


Table A1. Cont.

\begin{tabular}{|c|c|c|c|c|c|c|c|c|c|c|}
\hline & \multicolumn{5}{|c|}{ ALS Features } & \multicolumn{5}{|c|}{ Stereo-SAR Features } \\
\hline & $\min$ & $\max$ & range & mean & std.dev & $\min$ & $\max$ & range & mean & std.dev \\
\hline L_11.5 & 0.24 & 1 & 0.76 & 0.76 & 0.2 & 0 & 1 & 1 & 0.4 & 0.3 \\
\hline L_13.5** & 0.26 & 1 & 0.74 & 0.8 & 0.19 & 0 & 1 & 1 & 0.53 & 0.31 \\
\hline L_15.5 & 0.27 & 1 & 0.73 & 0.84 & 0.18 & 0 & 1 & 1 & 0.64 & 0.3 \\
\hline L_17.5 & 0.33 & 1 & 0.67 & 0.88 & 0.16 & 0 & 1 & 1 & 0.74 & 0.28 \\
\hline 3_highest & 2.53 & 30.33 & 27.8 & 18.01 & 5.8 & 6.95 & 34.45 & 27.5 & 18.99 & 5.7 \\
\hline FZ2_h10 & 0 & 20.52 & 20.52 & 9.38 & 4.07 & 2.7 & 19.5 & 16.8 & 7.92 & 3.4 \\
\hline FZ2_h20 & 0 & 23.82 & 23.82 & 11.14 & 4.55 & 3.2 & 25.73 & 22.53 & 9.76 & 4.08 \\
\hline FZ2_h30 * & 2.1 & 24.52 & 22.42 & 12.27 & 4.78 & 3.58 & 26.84 & 23.26 & 11.11 & 4.32 \\
\hline FZ2_h40 $* *$ & 2.1 & 25.35 & 23.25 & 13.14 & 4.99 & 4.16 & 27.55 & 23.39 & 12.23 & 4.49 \\
\hline FZ2_h50 & 2.37 & 25.73 & 23.36 & 13.84 & 5.11 & 4.33 & 28.83 & 24.5 & 13.2 & 4.62 \\
\hline FZ2_h60 & 2.37 & 26.08 & 23.71 & 14.55 & 5.26 & 4.99 & 29.22 & 24.23 & 14.19 & 4.86 \\
\hline FZ2_h70 & 2.37 & 26.68 & 24.31 & 15.21 & 5.36 & 5.91 & 30.42 & 24.51 & 15.17 & 5.06 \\
\hline FZ2_h80 & 2.6 & 27.26 & 24.66 & 15.94 & 5.46 & 6.22 & 33.96 & 27.74 & 16.38 & 5.4 \\
\hline FZ2_h85 & 2.6 & 27.91 & 25.31 & 16.38 & 5.51 & 6.43 & 33.96 & 27.53 & 17.08 & 5.65 \\
\hline FZ2_h90 & 2.6 & 28.28 & 25.68 & 16.83 & 5.57 & 6.48 & 34.68 & 28.2 & 17.75 & 5.68 \\
\hline FZ2_h95 & 2.6 & 28.56 & 25.96 & 17.37 & 5.63 & 6.68 & 34.68 & 28 & 18.48 & 5.77 \\
\hline FZ2_hMAX & 2.61 & 31.78 & 29.17 & 18.53 & 5.87 & 7.7 & 34.71 & 27.01 & 20.14 & 5.99 \\
\hline FZ2_p3 & 0 & 0.08 & 0.08 & 0.01 & 0.01 & 0 & 0.18 & 0.18 & 0.02 & 0.04 \\
\hline FZ2_p4 & 0 & 0.47 & 0.47 & 0.03 & 0.05 & 0 & 0.38 & 0.38 & 0.06 & 0.09 \\
\hline FZ2_p5 & 0 & 0.8 & 0.8 & 0.06 & 0.09 & 0 & 0.49 & 0.49 & 0.1 & 0.13 \\
\hline FZ2_p6 & 0 & 0.91 & 0.91 & 0.1 & 0.13 & 0 & 0.64 & 0.64 & 0.15 & 0.17 \\
\hline FZ2_p7 & 0 & 0.93 & 0.93 & 0.13 & 0.16 & 0 & 0.82 & 0.82 & 0.2 & 0.21 \\
\hline FZ2_p8 & 0 & 0.93 & 0.93 & 0.17 & 0.18 & 0 & 0.85 & 0.85 & 0.25 & 0.23 \\
\hline FZ2_p9 & 0 & 0.96 & 0.96 & 0.21 & 0.2 & 0 & 0.92 & 0.92 & 0.3 & 0.25 \\
\hline FZ2_p10 ** & 0 & 0.96 & 0.96 & 0.26 & 0.23 & 0 & 0.94 & 0.94 & 0.36 & 0.26 \\
\hline FZ2_VD & 0.05 & 1 & 0.95 & 0.79 & 0.17 & 0.38 & 1 & 0.62 & 0.94 & 0.1 \\
\hline FZ2_SD & 0.24 & 6.73 & 6.49 & 3.36 & 1.31 & 0.98 & 8.88 & 7.89 & 4.07 & 1.51 \\
\hline LZ2_h10 & 0 & 21.67 & 21.67 & 6.86 & 4.15 & - & - & - & - & - \\
\hline LZ2_h20 & 0 & 21.92 & 21.92 & 9.08 & 4.63 & - & - & - & - & - \\
\hline LZ2_h30 & 0 & 22.67 & 22.67 & 10.46 & 4.88 & - & - & - & - & - \\
\hline LZ2_h40 * & 0 & 23.81 & 23.81 & 11.71 & 4.88 & - & - & - & - & - \\
\hline LZ2_h50 & 0 & 24.23 & 24.23 & 12.63 & 5.11 & - & - & - & - & - \\
\hline LZ2_h60 & 0 & 26.49 & 26.49 & 13.46 & 5.44 & - & - & - & - & - \\
\hline LZ2_h70 & 0 & 27.31 & 27.31 & 14.19 & 5.63 & - & - & - & - & - \\
\hline LZ2_h80 & 0 & 27.69 & 27.69 & 15 & 5.92 & - & - & - & - & - \\
\hline LZ2_h85 & 0 & 28.14 & 28.14 & 15.36 & 6.03 & - & - & - & - & - \\
\hline LZ2_h90 & 0 & 28.56 & 28.56 & 15.74 & 6.17 & - & - & - & - & - \\
\hline LZ2_h95 & 0 & 29.28 & 29.28 & 16.16 & 6.38 & - & - & - & - & - \\
\hline LZ2_hMAX * & 0 & 31.78 & 31.78 & 17.32 & 6.23 & - & - & - & - & - \\
\hline LZ2_p3 & 0 & 0.12 & 0.12 & 0.01 & 0.02 & - & - & - & - & - \\
\hline LZ2_p4 & 0 & 0.3 & 0.3 & 0.02 & 0.03 & - & - & - & - & - \\
\hline LZ2_p5 & 0 & 0.55 & 0.55 & 0.03 & 0.05 & - & - & - & - & - \\
\hline LZ2_p6 & 0 & 0.76 & 0.76 & 0.05 & 0.07 & - & - & - & - & - \\
\hline LZ2_p7 & 0 & 0.79 & 0.79 & 0.06 & 0.08 & - & - & - & - & - \\
\hline
\end{tabular}


Table A1. Cont.

\begin{tabular}{|c|c|c|c|c|c|c|c|c|c|c|}
\hline & \multicolumn{5}{|c|}{ ALS Features } & \multicolumn{5}{|c|}{ Stereo-SAR Features } \\
\hline & $\min$ & $\max$ & range & mean & std.dev & $\min$ & $\max$ & range & mean & std.dev \\
\hline LZ2_p8 & 0 & 0.82 & 0.82 & 0.08 & 0.09 & - & - & - & - & - \\
\hline LZ2_p9 & 0 & 0.83 & 0.83 & 0.09 & 0.1 & - & - & - & - & - \\
\hline LZ2_p10 & 0 & 0.83 & 0.83 & 0.11 & 0.11 & - & - & - & - & - \\
\hline LZ2_VD & 0 & 0.92 & 0.92 & 0.35 & 0.22 & - & - & - & - & - \\
\hline LZ2_SD & 0 & 8.37 & 8.37 & 3.77 & 1.62 & - & - & - & - & - \\
\hline FZ05_h10 & 0.55 & 20.52 & 19.97 & 9.36 & 4.08 & 1.52 & 19.5 & 17.98 & 7.85 & 3.48 \\
\hline FZ05_h20 ** & 1.08 & 23.82 & 22.74 & 11.13 & 4.55 & 1.95 & 25.73 & 23.78 & 9.72 & 4.11 \\
\hline FZ05_h30 & 1.4 & 24.52 & 23.12 & 12.26 & 4.79 & 2.73 & 26.84 & 24.11 & 11.07 & 4.37 \\
\hline FZ05_h40 & 1.72 & 25.35 & 23.63 & 13.14 & 5 & 3.46 & 27.55 & 24.09 & 12.18 & 4.51 \\
\hline FZ05_h50 & 2.1 & 25.73 & 23.63 & 13.84 & 5.12 & 4.13 & 28.83 & 24.7 & 13.17 & 4.65 \\
\hline FZ05_h60 & 2.1 & 26.08 & 23.98 & 14.55 & 5.27 & 4.99 & 29.22 & 24.23 & 14.17 & 4.87 \\
\hline FZ05_h70 & 2.37 & 26.68 & 24.31 & 15.2 & 5.36 & 5.91 & 30.42 & 24.51 & 15.15 & 5.08 \\
\hline FZ05_h80 & 2.37 & 27.26 & 24.89 & 15.93 & 5.46 & 6.13 & 33.96 & 27.83 & 16.36 & 5.4 \\
\hline FZ05_h85 & 2.6 & 27.91 & 25.31 & 16.38 & 5.51 & 6.43 & 33.96 & 27.53 & 17.01 & 5.61 \\
\hline FZ05_h90 & 2.6 & 28.28 & 25.68 & 16.83 & 5.57 & 6.48 & 34.68 & 28.2 & 17.75 & 5.68 \\
\hline FZ05_h95 & 2.6 & 28.56 & 25.96 & 17.37 & 5.63 & 6.68 & 34.68 & 28 & 18.48 & 5.77 \\
\hline FZ05_hMAX & 2.61 & 31.78 & 29.17 & 18.53 & 5.87 & 7.7 & 34.71 & 27.01 & 20.14 & 5.99 \\
\hline FZ05_p1 & 0 & 0.04 & 0.04 & 0 & 0.01 & 0 & 0.09 & 0.09 & 0.01 & 0.02 \\
\hline FZ05_p2 & 0 & 0.11 & 0.11 & 0.01 & 0.01 & 0 & 0.48 & 0.48 & 0.03 & 0.06 \\
\hline FZ05_p3 & 0 & 0.16 & 0.16 & 0.01 & 0.02 & 0 & 0.6 & 0.6 & 0.05 & 0.08 \\
\hline FZ05_p4 & 0 & 0.47 & 0.47 & 0.04 & 0.05 & 0 & 0.71 & 0.71 & 0.09 & 0.12 \\
\hline FZ05_p5 & 0 & 0.8 & 0.8 & 0.07 & 0.1 & 0 & 0.77 & 0.77 & 0.13 & 0.16 \\
\hline FZ05_p6 & 0 & 0.91 & 0.91 & 0.1 & 0.13 & 0 & 0.85 & 0.85 & 0.18 & 0.2 \\
\hline FZ05_p7 & 0 & 0.93 & 0.93 & 0.14 & 0.16 & 0 & 0.92 & 0.92 & 0.23 & 0.23 \\
\hline FZ05_p8 & 0 & 0.93 & 0.93 & 0.18 & 0.19 & 0 & 0.94 & 0.94 & 0.28 & 0.26 \\
\hline FZ05_p9 & 0 & 0.96 & 0.96 & 0.22 & 0.21 & 0 & 0.96 & 0.96 & 0.33 & 0.28 \\
\hline FZ05_p10 & 0 & 0.96 & 0.96 & 0.27 & 0.23 & 0 & 0.96 & 0.96 & 0.39 & 0.28 \\
\hline FZ05_VD & 0.1 & 1 & 0.9 & 0.8 & 0.16 & 0.62 & 1 & 0.38 & 0.96 & 0.06 \\
\hline FZ05_SD & 0.75 & 8.04 & 7.29 & 3.46 & 1.32 & 0.98 & 8.88 & 7.89 & 4.22 & 1.55 \\
\hline LZ05_h10 & 0 & 21.67 & 21.67 & 6.71 & 4.2 & - & - & - & - & - \\
\hline LZ05_h20 & 0 & 21.92 & 21.92 & 9.01 & 4.63 & - & - & - & - & - \\
\hline LZ05_h30 & 0 & 22.67 & 22.67 & 10.44 & 4.88 & - & - & - & - & - \\
\hline LZ05_h40 & 0 & 23.81 & 23.81 & 11.69 & 4.89 & - & - & - & - & - \\
\hline LZ05_h50 & 0 & 24.23 & 24.23 & 12.62 & 5.08 & - & - & - & - & - \\
\hline LZ05_h60 & 0 & 26.49 & 26.49 & 13.44 & 5.42 & - & - & - & - & - \\
\hline LZ05_h70 & 0 & 27.31 & 27.31 & 14.19 & 5.6 & - & - & - & - & - \\
\hline LZ05_h80 & 0 & 27.69 & 27.69 & 15.02 & 5.87 & - & - & - & - & - \\
\hline LZ05_h85 & 0 & 28.14 & 28.14 & 15.38 & 5.96 & - & - & - & - & - \\
\hline LZ05_h90 & 0 & 28.56 & 28.56 & 15.77 & 6.09 & - & - & - & - & - \\
\hline LZ05_h95 & 0 & 29.28 & 29.28 & 16.19 & 6.3 & - & - & - & - & - \\
\hline LZ05_hMAX & 1.72 & 31.78 & 30.06 & 17.33 & 6.21 & - & - & - & - & - \\
\hline LZ05_p1 & 0 & 0.13 & 0.13 & 0.01 & 0.02 & - & - & - & - & - \\
\hline LZ05_p2 & 0 & 0.21 & 0.21 & 0.02 & 0.03 & - & - & - & - & - \\
\hline LZ05_p3 & 0 & 0.21 & 0.21 & 0.03 & 0.04 & - & - & - & - & - \\
\hline
\end{tabular}


Table A1. Cont.

\begin{tabular}{cccccc|ccccc}
\hline \multicolumn{7}{c}{ ALS Features } & \multicolumn{5}{c}{ Stereo-SAR Features } \\
\hline & min & max & range & mean & std.dev & min & max & range & mean & std.dev \\
\hline LZ05_p4 & 0 & 0.38 & 0.38 & 0.04 & 0.05 & - & - & - & - & - \\
LZ05_p5 & 0 & 0.63 & 0.63 & 0.05 & 0.07 & - & - & - & - & - \\
LZ05_p6 & 0 & 0.84 & 0.84 & 0.06 & 0.08 & - & - & - & - & - \\
LZ05_p7 & 0 & 0.87 & 0.87 & 0.08 & 0.09 & - & - & - & - & - \\
LZ05_p8 & 0 & 0.89 & 0.89 & 0.09 & 0.1 & - & - & - & - & - \\
LZ05_p9 & 0 & 0.91 & 0.91 & 0.11 & 0.1 & - & - & - & - & - \\
LZ05_p10 & 0 & 0.91 & 0.91 & 0.13 & 0.11 & - & - & - & - & - \\
LZ05_VD & 0.02 & 1 & 0.98 & 0.36 & 0.22 & - & - & - & - & - \\
LZ05_SD & 0 & 10.4 & 10.4 & 4.17 & 1.6 & - & - & - & - & - \\
\hline
\end{tabular}

Table A2. Abbreviations for ALS and SAR features.

\begin{tabular}{|c|c|}
\hline Feature & Explanation \\
\hline VD & $\begin{array}{l}\text { Vegetation density: number of vegetation points } \\
\text { (point height } \geq 2 \mathrm{~m} \text { )/number of all points. }\end{array}$ \\
\hline h85 & Vegetation height: 85 th percentile of the points above $z_{\min }=0.5 \mathrm{~m}$. \\
\hline HV_mean & $\begin{array}{l}\text { Mean height of all first-echo high vegetation }\left(\mathrm{HV}_{\text {threshold }}=5 \mathrm{~m}\right) \\
\text { points. }\end{array}$ \\
\hline HV_SD & $\begin{array}{l}\text { Standard deviation of the } z \text { coordinates of the first-echo high } \\
\text { vegetation }\left(\mathrm{HV}_{\text {threshold }}=5 \mathrm{~m}\right) \text { points. }\end{array}$ \\
\hline GR2/GR5/GR7_First & $\begin{array}{l}\text { Ratio of the number of ground first-echo points to the number of all } \\
\text { first-echo points. Ground threshold } 2,5 \text { or } 7 \mathrm{~m} \text {. }\end{array}$ \\
\hline GR2/GR5/GR7_Last & Identical to previous, but calculated from last-echo points. \\
\hline L_3.5-L_17.5 & $\begin{array}{l}\text { Ratio of the number of last-echo points with height } \leq \mathrm{h}_{\max } \text { to the } \\
\text { number of all last-echo points, where } \mathrm{h}_{\max }=3.5,5.5,7.5, \ldots, 17.5 \mathrm{~m} \text {. }\end{array}$ \\
\hline 3_highest & Mean height of the three highest first-echo points. \\
\hline FZ05_h\#/FZ2_h\#\# & $\begin{array}{l}\text { Height of the point for which the cumulative height sum of ordered } \\
\text { points is closest to } h \% \text { of the total height sum. Low points } \\
\text { ( } \mathrm{z}_{\min }=0.5 \mathrm{~m} \text { (FZ05) or } \mathrm{z}_{\min }=2 \mathrm{~m}(\mathrm{FZ2}) \text { ) and points outside of } \\
\text { allowed ALS echoes (first, only) are excluded. }\end{array}$ \\
\hline FZ05_p\#/FZ2_p\# & $\begin{array}{l}\text { Number of points with height } \leq p \text { meters/number of all points. Low } \\
\text { points and points outside of allowed ALS echoes are excluded. }\end{array}$ \\
\hline FZ05_VD/FZ2_VD & Ratio of the number of points above $\mathrm{z}_{\min }$ to the number of all points. \\
\hline FZ05_SD/FZ2_SD & Standard deviation of the $z$ coordinates of points above $\mathrm{z}_{\min }$. \\
\hline LZ05_\#/LZ2_\# & $\begin{array}{l}\text { Identical to FZ05/FZ2 features, but calculated from last and only } \\
\text { ALS echoes. The features are not calculated for the SAR data. }\end{array}$ \\
\hline
\end{tabular}

(C) 2014 by the authors; licensee MDPI, Basel, Switzerland. This article is an open access article distributed under the terms and conditions of the Creative Commons Attribution license (http://creativecommons.org/licenses/by/3.0/). 